\title{
Relationship between Acculturation Attitude and Translation of Culture-Bound Texts
}

\author{
Vahid Rafieyan \\ International College of Liberal Arts, Yamanashi Gakuin University \\ Kofu, Yamanashi, Japan \\ E-mail: rafieyanv@ygu.ac.jp
}

Received: Feb. 3, 2016 Accepted: May 9, 2016 Published: May 9, 2016

doi:10.5296/jse.v6i2.9402 URL: http://dx.doi.org/10.5296/jse.v6i2.9402

\begin{abstract}
Acculturation attitudes, referred to as "sojourner reactions to adaptation into new language and cultural communities" (Culhane, 2004: 51), can be a predictor of translators' level of intercultural competence during educational sojourns. Intercultural competence, defined as a "complex of abilities needed to perform effectively and appropriately when interacting with others who are linguistically and culturally different from oneself" (Fantini 2006: 12), can accordingly be a predictor of translation quality. To assess the actual relationship between acculturation attitude and quality of translation of culture-bound texts, the current study was conducted on 82 Iranian postgraduate students of Master of English translation at universities in England. The East Asian Acculturation Measure (EAAM), developed by Berry (2001), was adapted to assess translation students' level of acculturation attitudes toward English culture. Some news excerpts adopted from the British Broadcasting Corporation (BBC) were also selected to assess the quality of translation of culture-bound texts. The analysis of Spearman rank order correlation (rho) revealed the significant positive relationship between acculturation attitude and quality of translation of culture-bound texts. The pedagogical implications of the findings suggested encouraging and providing language learners with opportunities to assimilate or integrate into the host country culture to be able to develop their intercultural competence to an optimal level.
\end{abstract}

Keywords: Acculturation Attitude, Educational Sojourn, Intercultural Competence, Translation Quality 


\section{Introduction}

Language is culturally embedded: it serves to express and shape cultural reality, and the meanings of linguistic units can only be understood when considered together with the cultural contexts in which they arise, and in which they are used. In translation, therefore, not only two languages but also two cultures invariably come into contact. In this sense, then, translation is a form of intercultural communication. Over and above recognizing the importance of the two larger macro-cultural frameworks, however, the translator must of course also consider the more immediate 'context of situation' (House, 2015). Intercultural competence, defined as a "complex of abilities needed to perform effectively and appropriately when interacting with others who are linguistically and culturally different from oneself" (Fantini 2006: 12), can be accordingly best developed in translators through educational sojourns, defined as "periods spent abroad in a region where a target language is used as a medium of everyday communication" (Culhane, 2004: 50). Effects of educational sojourns are especially evident when the translators assimilate into the source language culture adopting assimilation attitude of acculturation toward source language culture. Therefore, acculturation attitudes, referred to as "sojourner reactions to adaptation into new language and cultural communities" (Culhane, 2004: 51), can be a predictor of translators' level of intercultural competence during educational sojourns.

Acculturation attitudes were presented in a model developed by Berry (1980) in which the different ways that people acculturate is outlined. There are two major issues in this model: the extent to which people tend to maintain their heritage culture and the extent to which people tend to have contact with the people of the target society and adopt the culture of the target society. The level of tendency toward either of these two issues leads to the adoption of four acculturation strategies. These four acculturation strategies consist of assimilation, integration, separation, and marginalization. Assimilation is the acculturation strategy in which people do not tend to maintain their heritage culture but tend to have close contact with the people of the target society and adopt the culture of the target society. Integration is the acculturation strategy in which people tend to maintain their heritage culture and adopt the culture of the target society and have close contact with the people of the target society. Separation is the acculturation strategy in which people tend to maintain their heritage culture but avoid adopting the culture of the target society and having contact with the people of the target society. Marginalization is the acculturation strategy in which people neither tend to maintain their heritage culture nor tend to adopt the culture of the target society and have contact with the people of the target society (Sam \& Berry, 2010). 
Table 1. Acculturation Strategies

\begin{tabular}{llll}
\hline & + & \multicolumn{2}{c}{ Maintenance of Heritage Culture } \\
Adoption of Target Culture & $\uparrow$ & Assimilation \\
& $\downarrow$ & Separation & Marginalization \\
& - & \\
\hline
\end{tabular}

Language learners' acculturation attitudes have been investigated in a number of studies. In one study, Jiang et al. (2009) examined the effects of acculturation attitude on language learners' pronunciation and oral speaking proficiency. The participants of the study consisted of a group of Chinese international students enrolled in a university in the United States. Data were collected through the Stephenson Multigroup Acculturation Scale to measure participants' acculturation attitudes, a sentence reading task to assess pronunciation ability, and a language proficiency interview to measure oral speaking proficiency. Findings of the study suggested that participants were unanimously more immersed in their heritage culture but varied on their acculturation toward American society. The degree of immersion in American society contributed to participants' speaking proficiency but did not contribute to improvements in pronunciation. In another study, Cara (2010) explored acculturation strategies of a group of ethnic Russian adolescents in Latvia two years before and three years after the 2004 education reform as well as the relationship between the choice of acculturation strategies and Latvian language knowledge and use. Knowledge of Latvian language was assessed through a 3-item four-point scale questionnaire assessing speaking, writing, and reading skills. Measure of acculturation strategy was also adopted from the ICSEY project that assessed four acculturation strategies including assimilation, integration, separation, and marginalization on a four-point scale. The findings of the study suggested that integration was the most preferred strategy while marginalization was the least preferred strategy in both years of the study. Furthermore, Latvian language knowledge and use were positively correlated with assimilation and integration strategies but negatively correlated with separation and marginalization strategies. Waniek-Klimczak (2011) also conducted a study to investigate the acculturation attitudes of three Polish learners of English in an educational sojourn in England following five years of residence in the target language country. Data were collected qualitatively through an open-format questionnaire consisting of items related to both language learners' language experience and their acculturation strategies. Findings of the study revealed that both assimilation and integration were adopted as acculturation strategies by the three Polish language learners. Moreover, language learners expressed that exposure to authentic culturally specific materials was more useful than formal training they had received in English language classes. Rafieyan et al. (2014) conducted another study to explore the acculturation attitudes of language learners on an academic sojourn. Participants of the study consisted of a group of Iranian undergraduate students of English during a semester-long academic exchange program in a university in the United 
States. Data were collected through an acculturation attitude questionnaire consisting of four subscales including assimilation, integration, separation, and marginalization attitudes. Findings of the study revealed that Iranian sojourners in the United States had a high level of acculturation attitude toward the culture of the target language society. Taguchi (2015) was the other researcher who investigated the relationship between language learners' entry-level cross-cultural adaptability and their gains in pragmatic competence in study abroad. Participants of her study were a group of international students enrolled in a Japanese language program in a university in Japan. Cross-cultural adaptability was assessed through the Cross-Cultural Adaptability Inventory (CCAI) developed by Kelly and Meyers (1995). An oral discourse completion test was also used to measure speech act production. The study found that cross-cultural adaptability was significantly related to the development of pragmatic competence. In their other study, Rafieyan et al. (2015a) investigated the relationship between acculturation attitude and the ability to comprehend target language implied meanings referred to as pragmatic comprehension. Participants in the study consisted of a group of Iranian undergraduate students of English in universities in Australia. Data were collected through a Likert scale acculturation attitude questionnaire and a multiple choice pragmatic comprehension test. The findings of the study revealed a strong positive relationship between degree of acculturation attitude toward target language culture and pragmatic comprehension ability. Finally, Rafieyan (in press) conducted a study to explore the relationship between acculturation attitude and the effectiveness of pragmatic instruction. Participants of the study consisted of a group of postgraduate international students of English at a university in Australia. Data were collected through a discourse completion task developed by Bardovi-Harlig (2009) testing participants' pragmatic competence and the modified version of the East Asian Acculturation Measure developed by Berry (2001) assessing their acculturation attitudes. The results of the correlation analysis revealed a strong positive relationship between acculturation attitude and effectiveness of pragmatic instruction.

The studies conducted so far have investigated either language learners' acculturation attitudes or the relationship between acculturation attitude and linguistic and pragmatic competencies. There is, however, a dearth of research on assessing the relationship between acculturation attitude and translation quality. Therefore, given the significance of possessing a high level of intercultural competence on the quality of translation of culture-bound texts on one hand and the significance of having a high level of acculturation attitude toward source language culture during educational sojourn to develop intercultural competence on the other hand, the current study seeks to investigate the relationship between translation students' acculturation attitudes during educational sojourn and the quality of their translation of culture-bound texts. In this respect, the research question to be addressed in the current study is:

Is there any relationship between translation students' acculturation attitudes and the quality of their translations?

Accordingly the null hypothesis is: 
There is no relationship between translation students' acculturation attitudes and the quality of their translations.

\section{Methodology}

\subsection{Participants}

Participants of the study consisted of 82 (32 males and 50 females) Iranian postgraduate students of Master of English translation at universities in England. They were all at the second semester of their studies and had experienced living in England for more than six months. A minimum of six months residence in the target culture was adopted as according to the U-curve theory of adjustment and the concept of culture shock (Black \& Mendenhall, 1990; Lysgaard, 1955; Oberg, 1960), during the first six months, referred to as the 'honeymoon' stage, expatriates are excited with the new and interesting aspects offered by the host country and the feelings of being a tourist cannot be avoided (Black \& Mendenhall, 1990). It is from the sixth months up to one year, referred to as the 'crisis' stage, that the expatriates are expected to be more susceptible to the feelings of despair and the tolls of adjusting become apparent (Copeland \& Giggs, 1985).

\subsection{Instruments}

To assess translation students' level of acculturation attitude toward English culture, the East Asian Acculturation Measure (EAAM), developed by Berry (2001), was adapted. The questionnaire consisted of 29 items with four subscales: assimilation attitude (items 1-8), integration attitude (items 9-13), separation attitude (items 14-20), and marginalization attitude (items 21-29). The items were based on a Likert scale ranging from strongly disagree to strongly agree with values 1 to 5 assigned to them respectively. In this respect, the value of 1 was assigned to 'strongly disagree', the value of 2 was assigned to 'disagree', the value of 3 was assigned to 'neutral', the value of 4 was assigned to 'agree', and the value of 5 was assigned to 'strongly agree'. The original questionnaire had been designed for a group of Asians including Chinese, Japanese, and Korean immigrants to America. In the adapted version of the questionnaire, 'Asian' was replaced by 'Iranian' and 'American' was replaced by 'English'.

To assess the quality of translation of culture-bound texts, some news excerpts were selected from The British Broadcasting Corporation (BBC) which is the public service broadcaster of the United Kingdom. The criterion for selection of news excerpts was the existence of abundant British cultural features. The researcher carefully reviewed current news on the website of BBC and selected news excerpts which contained a large quantity of British cultural features. Moreover, to avoid making the translation task tedious for participants and consequently ensure that participants will focus on rendering a high quality translation of the news excerpts to the best of their knowledge, the length of the selected news was kept within a page limit (325 words).

To examine the validity of both instruments, content-related evidence of validity was used. The researcher wrote out the definition of what he wanted to measure and then gave this definition, along with the adapted acculturation attitude questionnaire and the culture-bound 
text and a description of the intended sample, to two professors at a university in Iran who were experts in the field of translation. The professors confirmed that the content and format of both instruments were consistent with the definition of the variable and the sample of objects to be measured (Fraenkel et al., 2012). To examine the reliability of both instruments, a pilot study was conducted with 24 nonparticipant Iranian students of Master of English translation at universities in England. The reliability coefficient of the adapted acculturation attitude questionnaire and the culture-bound text assessed through Cronbach's alpha were respectively 0.80 and 0.82 .

\subsection{Procedure}

During the second semester of the academic year 2015/2016, 82 copies of the culture-bound text to be translated were distributed among all 82 students of English translation participating in the study. Participants were neither informed of the existence of the cultural references of Great Britain in the culture-bound text nor alerted of the significant weight of appropriate transference of these cultural references into the target language according to the sociolinguistic and sociocultural features of the target language in assessing the quality of their translations. Participants were given ample time to render a high quality of translation of culture-bound text to the best of their knowledge and were allowed to use any type of dictionaries they wished to use during the translation task. Immediately following the completion of the translation task, 82 copies of the acculturation attitude questionnaire were distributed among all of the participants. The participants were guided to answer each item on the questionnaire by selecting the point on the scale which best reflected their attitudes toward the idea expressed by the item. Again, they were given ample time to reflect on the items and complete the acculturation attitude questionnaire. At the end, all translations and acculturation attitude questionnaires were collected by the researcher and prepared for the subsequent data analysis.

\subsection{Data Analysis}

To measure acculturation attitude of participants, descriptive statistics were used to describe and summarize the properties of the data collected from the participants. Descriptive statistics consisted mainly of mean and standard deviation. The acculturation attitude was represented by a mean score on a 5-point scale, where 1 (strongly disagree) represented the minimum score on the scale and 5 (strongly agree) represented the maximum score on the scale. The overall mean score for each acculturation strategy determined participants' level of attitude regarding that specific strategy. The acculturation strategy which received the highest mean score represented language learners' acculturation attitude. For the purpose of correlation analysis, higher values were assigned to the acculturation strategies which represented a higher attitude toward target culture and lower values were assigned to the acculturation strategies which represented a higher attitude toward heritage culture. In this respect, the value of 1 was assigned to marginalization attitude, the value of 2 was assigned to separation attitude, the value of 3 was assigned to integration attitude, and the value of 4 was assigned to assimilation attitude.

To measure the quality of translations, two professors who were experts in the field of 
translation rated the quality of translations based on a 5-point scale ranging from 'very bad' to 'very good' with values 1 to 5 assigned to them respectively. In this respect, the value of 1 was assigned to 'very bad', the value of 2 was assigned to 'bad', the value of 3 was assigned to 'neither good nor bad', the value of 4 was assigned to 'good', and the value of 5 was assigned to 'very good'. Quality of translations was assessed based on House's $(1977,1997)$ functional-pragmatic model which consisted of three steps: (1) the source text was analyzed along the dimensions of Field, Tenor, and Mode. On the basis of findings on the lexical, the syntactic, and the textual level, a text-profile was set up which reflected the individual textual function; (2) the translated text was analyzed along the same dimensions and at the same level of delicacy; (3) the source and translation texts were compared. An assessment of their relative match was established: how the two texts were similar and/or different, given differing linguistic and cultural constraints (Thuy, 2013).

To measure the degree of agreement between the ratings assigned by the two raters, the inter-rater reliability was assessed through Cohen's Kappa which is a measure of inter-rater reliability used to measure agreement between two coders (Saldanha \& O'Brien, 2014). The analysis of Cohen's Kappa would give a value between -1 and +1 . The interpretation of the values obtained through Cohen's Kappa, according to Landis and Koch (1977), are presented in Table 2. The inter-rater reliability assessed for the translations was 0.88 which, according to the guidelines set by Landis and Koch (1977), indicates an almost perfect agreement between the two raters. For cases which received different ratings, the raters discussed until they reached an agreement.

Table 2. Interpretation of Cohen's Kappa Values

\begin{tabular}{ll}
\hline Values & Interpretation \\
\hline Smaller than 0.00 & Poor Agreement \\
\hline 0.00 to 0.20 & Slight Agreement \\
\hline 0.21 to 0.40 & Fair Agreement \\
\hline 0.41 to 0.60 & Moderate Agreement \\
\hline 0.61 to 0.80 & Substantial Agreement \\
\hline 0.81 to 1.00 & Almost Perfect Agreement \\
\hline
\end{tabular}

To measure the relationship between translation students' level of acculturation attitudes and the quality of their translation of culture-bound text, Spearman rank order correlation (rho), which measures the relationship between two variables when both variables are measured on ordinal scales (Gravetter \& Wallnau, 2013), was used. The size of the value of Spearman correlation can range from -1.00 to +1.00 . This value indicates the strength of the relationship between the two variables. A value of 0.00 indicates no relationship at all, a value of +1.00 indicates a perfect positive correlation (as one variable increases, so does the other variable), and a value of -1.00 indicates a perfect negative correlation (as one variable increases, the other variable decreases) (Pallant, 2013). Cohen (1988) suggests a set of guidelines to interpret the values between 0.00 and 1.00. The guidelines, which have been presented in Table 3, apply whether or not there is a negative sign in front of the correlation value. 
Table 3. Strength of Relationship

\begin{tabular}{ll}
\hline Correlation Value & Interpretation \\
\hline $0.10-0.29$ & Small Correlation \\
\hline $0.30-0.49$ & Medium Correlation \\
\hline $0.50-1.00$ & Large Correlation \\
\hline
\end{tabular}

The squared correlation $\left(\mathrm{r}^{2}\right)$, called the coefficient of determination, was then used to measure the proportion of variability in quality of translation of culture-bound text that can be determined from its relationship with acculturation attitude. Squared correlation would give a value ranging from 0.00 to 1.00 . Cohen (1988) has also suggested a set of guidelines to interpret the values of squared correlation. The criterion for interpreting the value of squared correlation, as proposed by Cohen (1988), has been presented in Table 4.

Table 4. Percentage of Variance Explained

\begin{tabular}{ll}
\hline Squared Correlation Value & Interpretation \\
\hline 0.01 & Small Correlation \\
\hline 0.09 & Medium Correlation \\
\hline 0.25 & Large Correlation \\
\hline
\end{tabular}

\section{Results}

Table 5 presents the descriptive presentation of acculturation attitudes of translation students participating in the study. Descriptive data presented in the table consist of the number and percentage of participants in each acculturation attitude. According to the descriptive data, integration attitude accommodated the highest number of participants (58.53 percent) while marginalization attitude accommodated the lowest number of participants ( 2.44 percent). As the data show, the majority of participants (73.16 percent) were interested in source language culture adopting assimilation and integration acculturation attitudes whereas the minority of participants (26.84 percent) avoided source language culture adopting separation and marginalization acculturation attitudes.

Table 5. Descriptive Presentation of Acculturation Attitudes

\begin{tabular}{lcc}
\hline Acculturation Attitude & Number of Participants & Percentage of Participants \\
\hline Assimilation & 12 & 14.63 \\
\hline Integration & 48 & 58.53 \\
\hline Separation & 20 & 24.40 \\
\hline Marginalization & 2 & 2.44 \\
\hline
\end{tabular}

Table 6 presents the descriptive presentation of quality of translation of culture-bound text for translation students participating in the study. Descriptive data presented in the table consist of the number and percentage of participants for each translation quality. According to the descriptive data, the majority of participants presented their translations of the culture-bound text at an average and above level. As the data show, 36.59 percent of participants presented 
their translations at an above average level of quality (good and very good levels), 42.68 percent of participants presented their translations at an average level of quality, and 20.73 percent of participants presented their translations at a below average level of quality (bad and very bad levels).

Table 6. Descriptive Presentation of Translation Quality

\begin{tabular}{lcc}
\hline Translation Quality & Number of Participants & Percentage of Participants \\
\hline Very Good & 7 & 8.54 \\
\hline Good & 23 & 28.05 \\
\hline Neither Good Nor Bad & 35 & 42.68 \\
\hline Bad & 17 & 20.73 \\
\hline Very Bad & 0 & 0 \\
\hline
\end{tabular}

Table 7 presents the results of Spearman rank order correlation (rho) analysis for translation students' level of acculturation attitudes and the quality of their translations of culture-bound text. The first thing to consider in correlation analysis is the direction of the relationship between the variables (acculturation attitude and translation quality). The data show that there is a positive relationship between the two variables, that is, the higher the attitude toward source language culture the higher the quality of translation. The second thing to consider in correlation analysis is the size of the value of the correlation coefficient. This value will indicate the strength of the relationship between the two variables (acculturation attitude and translation quality). The value of correlation coefficient obtained in the analysis of Spearman rank order correlation (rho) is 0.56 which according to the guidelines proposed by Cohen (1988) to interpret the values of correlation coefficient suggests quite a strong relationship between acculturation attitude and quality of translation.

Table 7. Correlation

\begin{tabular}{|c|c|c|c|c|}
\hline & & & $\begin{array}{c}\text { Acculturation } \\
\text { Attitude }\end{array}$ & $\begin{array}{c}\text { Translation } \\
\text { Quality }\end{array}$ \\
\hline \multirow[t]{6}{*}{ Spearman's rho } & \multirow{3}{*}{$\begin{array}{l}\text { Acculturation } \\
\text { Attitude }\end{array}$} & Correlation Coefficient & 1.000 & $0.560 * *$ \\
\hline & & Sig. (2-tailed) & & 0.000 \\
\hline & & $\mathrm{N}$ & 82 & 82 \\
\hline & \multirow{3}{*}{$\begin{array}{l}\text { Translation } \\
\text { Quality }\end{array}$} & Correlation Coefficient & $0.560 * *$ & 1.000 \\
\hline & & Sig. (2-tailed) & 0.000 & \\
\hline & & $\mathrm{N}$ & 82 & 82 \\
\hline
\end{tabular}

To get an idea of how much variance the two variables (acculturation attitude and translation quality) share, the coefficient of determination was calculated. This can be obtained by squaring the correlation value. The coefficient of determination for the obtained correlation analysis is $r^{2}=(0.56)^{2}=0.3136$ which according to the guidelines proposed by Cohen (1988) to interpret the values of coefficient of determination suggests a large correlation coefficient. To convert the value of coefficient of determination to 'percentage of variance', it was 
multiplied by 100 , that is, $\mathrm{r}^{2}=(0.56)^{2} \times 100=31.36$. This suggests that acculturation attitude helps to explain nearly 31 percent of the variance in translation students' quality of translation.

\section{Discussion}

The study found that the translation students participating in the study were more immersed in the source language culture than their heritage culture. The study also found that there is a strong positive relationship between acculturation attitude and quality of translation of culture-bound texts. Translation students who were more immersed in source language culture adopting assimilation and integration acculturation attitudes presented their translation of culture-bound text at a higher quality than translation students who were more immersed in their heritage culture adopting separation and marginalization acculturation attitudes. Therefore, the null hypothesis of the study which states that there is no relationship between translation students' acculturation attitudes and the quality of their translations is rejected.

These findings can be explained through the fact that more exposure to source language cultural features and contact with source language speakers can result in more gains in the knowledge of cultural features of the source language and the subsequent ability to transfer the meaning of source language cultural references to target language according to the sociolinguistic and sociocultural rules of the target language. Translation students who were more assimilated and integrated in the source language culture definitely had more opportunities to immerse in source language culture and interact with source language speakers to learn the sociolinguistic and sociocultural features of the source language than translation students who were more marginalized and separated from the source language culture. Consequently, they must have managed to develop their intercultural competence to a greater extent and present their translation of culture-bound text at a higher level of quality.

These findings can be also explained through Schmidt's (1990, 1995, 2001) noticing hypothesis which states that "people learn about the things that they attend to and do not learn much about the things they do not attend to" (Schmidt, 2001: 30). Translation students who were more interested in learning the sociolinguistic and sociocultural features of the source language society adopting assimilation and integration acculturation attitudes certainly noticed and paid attention to the sociolinguistic and sociocultural features of the source language society to a greater extent than translation students who were less interested in learning the sociolinguistic and sociocultural features of the source language culture adopting separation and marginalization acculturation attitudes during their academic sojourn. Consequently, their noticing of and attention to the source language sociolinguistic and sociocultural features must have led them to more gains in cultural knowledge of the source language society and the application of their obtained knowledge to present their translation of cultural references of the source language in more culturally suitable and sensible ways for the target language readers.

The findings obtained in the current study are consistent with the findings obtained in the study conducted by Rafieyan et al. (2014) who found that Iranian sojourners in the United 
States had a high level of acculturation attitude toward the culture of the target language society. The findings obtained in the current study also support the findings obtained in the studies conducted by Jiang et al. (2009) and Cara (2010) who found that language learners who were more immersed in target language culture adopting assimilation and integration acculturation strategies gained more target language knowledge than language learners who were less immersed in target language culture adopting separation and marginalization acculturation strategies. These findings are also in line with the findings obtained by Taguchi (2015), Rafieyan et al. (2015a), and Rafieyan (in press) who found a strong positive relationship between degree of acculturation attitude toward source language culture and pragmatic competence.

\section{Conclusion}

The study revealed a significant positive relationship between acculturation attitude and quality of translation of culture-bound texts. Translation students who were more immersed in the source language culture adopting assimilation and integration acculturation attitudes presented a higher quality of translation of culture-bound text than translation students who were less immersed in the source language culture adopting separation and marginalization acculturation attitudes. Therefore, language learners who are on educational sojourns should be encouraged and provided with opportunities to assimilate or integrate into the host country culture to be able to develop their intercultural competence to an optimal level (Rafieyan et al., 2015a; Rafieyan et al., 2015b; Rafieyan, in press).

The study was limited in two ways. First of all, the study did not include participants of several nationalities with varying cultural backgrounds to be able to generalize the findings to translators of all nationalities. Secondly, the study merely followed a cross-sectional design and did not include a cultural intervention to assess the level of cultural gains by participants of different acculturation attitudes during their academic sojourn. Therefore, future studies are recommended to include translation students of various cultural backgrounds during an educational sojourn accompanied with a cultural intervention.

\section{Acknowledgement}

The author would like to acknowledge the contribution of Ahmad Rafieyan.

\section{References}

Bardovi-Harlig, K. (2009). Conventional Expressions as a Pragmalinguistic Resource: Recognition and Production of Conventional Expressions in L2 Pragmatics. Language Learning, 59(4), 755-795. http://dx.doi.org/10.1111/j.1467-9922.2009.00525.x

Berry, D. T. (2001). Development of a New Scale for Measuring Acculturation: The East Asian Acculturation Measure (EAAM). Journal of Immigrant Health, 3(4), 38-55.

Berry, J. W. (1980). Acculturation as Varieties of Adaptation: The Role of Cultural Awareness and Ethnic Loyalty in Acculturation. In A. M. Padilla (Ed.), Acculturation: Theory, Models and Some New Findings (pp. 9-25). Boulder, CO: Westview Press.

Black, J. S., \& Mendenhall, M. (1990). Cross-Cultural Training Effectiveness: A Review and 
Theoretical Framework for Future Research. Academy of Management Review, 15(1), $113-136$.

Cara, O. (2010). The Acculturation of Russian-Speaking Adolescents in Latvia: Language Issues Three Years after the 2004 Education Reform. European Education, 42(1), 8-36. http://dx.doi.org/10.2753/EUE1056-4934420101

Cohen, J. (1988). Statistical Power Analysis for the Behavioral Sciences. Hillsdale, NJ: Lawrence Erlbaum Associates.

Copeland, L., \& Griggs, L. (1985). Going International: How to Make Friends and Deal Effectively in the Global Marketplace. Nueva York: Plume.

Culhane, S. F. (2004). An Acculturation Interaction Model: Acculturation Attitudes in Second Language Acquisition. Electronic Journal of Foreign Language Teaching, 1(1), 50-61.

Fantini, A. E. (2006). Exploring and Assessing Intercultural Competence. Retrieved 15 February 2012, from http://www.sit.edu/publications/docs/feil_research_report.pdf

Fraenkel, J. R., Wallen, N. E., \& Hyun, H. H. (2012). How to Design and Evaluate Research in Education (8th ed.). New York: McGraw-Hill.

Gravetter, F. J., \& Wallnau, L. B. (2013). Statistics for the Behavioral Sciences. Belmont, C A: Wadsworth Publishing.

House, J. (1977). A Model for Translation Quality Assessment. Tubingen: Narr.

House, J. (1997). Translation Quality Assessment: A Model Revisited. Tubingen: Narr.

House, J. (2015). Translation Quality Assessment: Past and Present. New York: Routledge.

Jiang, M., Green, R. J., Henley, T. B., \& Masten, W. G. (2009). Acculturation in Relation to the Acquisition of a Second Language. Journal of Multilingual and Multicultural Development, 30(6), 481-492. http://dx.doi.org/10.1080/01434630903147898

Kelley, C., \& Meyers, J. (1995). Cross-Cultural Adaptability Inventory Manual. Arlington, VA: Vangent.

Landis, J. R., \& Koch, G. G. (1977). The Measurement of Observer Agreement for Categorical Data. Biometrics, 33(1), 159-174. http://dx.doi.org/10.2307/2529310

Lysgaard, S. (1955). Adjustment in Foreign Society: Norwegian Fulbright Grantees Visiting the United States. International Social Science Bulletin, 7(1), 45-51.

Oberg, K. (1960). Culture Shock: Adjustment to New Cultural Environment. Practical Anthropologist, 7, 177-182.

Pallant, J. (2013). SPSS Survival Manual: A Step by Step Guide to Data Analysis Using SPSS Program (5th ed.). Australia: Allen \& Unwin.

Rafieyan, V., Orang, M., Bijami, M., Sharafi-Nejad, M., \& Lin, S. E. (2014). Language Learners' Acculturation Attitudes. English Language Teaching, 7(1), 114-119.

Rafieyan, V., Behnammohammadian, N., \& Orang, M. (2015a). Relationship between Acculturation Attitude and Pragmatic Comprehension. Journal of Language Teaching and Research, 6(3), 504-512. http://dx.doi.org/10.17507/jltr.0603.05 
Rafieyan, V., Golerazeghi, H., \& Orang, M. (2015b) Relationship between Cultural Intelligence and Pragmatic Comprehension. Journal of Language Teaching and Research, 6(3). 560-565. http://dx.doi.org/10.17507/j1tr.0603.11

Rafieyan, V. (in press). Relationship between Acculturation and Effectiveness of Pragmatic Instruction.

Saldanha, G., \& O'Brien, S. (2014). Research Methodologies in Translation Studies. New Tork, NY: Routledge.

Sam, D. L., \& Berry, J. W. (2010). Acculturation: When Individuals and Groups of Different Cultural Backgrounds Meet. Perspectives on Psychological Science, 5(4), 472-481. http://dx.doi.org/10.1177/1745691610373075

Schmidt, R. W. (1990). The Role of Consciousness in Second Language Learning. Applied Linguistics, 11(2), 129-158. http://dx.doi.org/10.1093/applin/11.2.129

Schmidt, R. W. (1995). Consciousness and Foreign Language Learning: A Tutorial on the Role of Attention and Awareness in Learning. In R. W. Schmidt (Ed.), Attention and Awareness in Foreign Language Learning (Technical Report No. 9, pp. 1-63). University of Hawaii: Honolulu.

Schmidt, R. W. (2001). Attention. In P. Robinson (Ed.), Cognition and Second Language Instruction (pp. 3-32). Cambridge: Cambridge University Press. http://dx.doi.org/10.1017/CBO9781139524780.003

Taguchi, N. (2015). Cross-Cultural Adaptability and Development of Speech Act Production in Study Abroad. International Journal of Applied Linguistics, 25(3), 343-365. http://dx.doi.org/10.1111/ijal.12073

Thuy, P. T. (2013). House's Functional-Pragmatic Model of Translation Assessment and Implications for Evaluating English-Vietnamese Translation Quality. VNU Journal of Foreign Studies, 29(1), 56-64.

Waniek-Klimczak, E. (2011). Acculturation Strategy and Language Experience in Expert ESL Speakers: An Exploratory Study. Studies in Second Language Learning and Teaching, 1(2), 227-245. http://dx.doi.org/10.14746/ssllt.2011.1.2.4

\section{Copyright Disclaimer}

Copyright for this article is retained by the author(s), with first publication rights granted to the journal.

This is an open-access article distributed under the terms and conditions of the Creative Commons Attribution license (http://creativecommons.org/licenses/by/3.0/). 